\title{
Platform capitalism
}

\section{Nick Srnicek}

Cambridge: Polity Press, 2017, 171 p. ISBN: 978-1-5095-0486-2; 978-1-5095-0487-9 (pb)

\section{Victo José da Silva Neto* (iD}

* Universidade Estadual de Campinas (Unicamp), Campinas (SP), Brasil. E-mail: victoneto@ige.unicamp.br

Nick Srnicek, professor de economia digital do departamento de digital humanities do King's College, publicou em 2017 o livro Platform capitalism. As linhas de pesquisa do autor são economia marxista, economia de plataformas, políticas antitrabalho e economia política da inteligência artificial. Com exceção do último, estes temas aparecem direta ou indiretamente nas páginas desta obra, ${ }^{1}$ em que o autor defende o argumento de que estaríamos em uma nova fase do capitalismo, na qual a exploraçáo econômica dos dados ocupa lugar central nos novos empreendimentos privados (SRNICEK, 2017, p. 6). A hipótese que fundamenta o livro é a de que o poder de agência responsável por transportar a economia para esta nova fase coube às grandes empresas de tecnologia (SRNICEK, 2017, p. 3). Srnicek se debruça sobre o novo modelo de negócios adequado a um capitalismo voltado para a exploração econômica dos dados: plataformas. A justificativa do autor para este foco é a necessidade de vislumbrar se este novo conjunto de tecnologias e modelos organizacionais representa um novo regime de acumulação ou a continuação de regimes precedentes (SRNICEK, 2017, p. 7). Cada regime teria uma forma própria de crise e de relação

1 A mençăo a economistas clássicos se restringe a Marx, Baran e Sweezy, expoentes do marxismo; a postura de Srnicek, contrária à solução de se realizar micropagamentos pela geração, uso e exploração dos dados de terceiros nas plataformas digitais, revela sua preferência por açốes e diretrizes que permitam à sociedade superar o atual modo de produção (regido pela lógica instrumental e mercadológica) - em vez de repará-lo. 
capital-trabalho, elementos valiosos para se pensar estratégias políticas alternativas ao modo de produção capitalista vigente.

O livro coleta informaçôes ricas e interessantes sobre as plataformas, além de propor uma visão crítica sobre o novo regime. É preciso ressaltar seu entendimento de que novas tecnologias e novas oportunidades só se materializam com a emergência de novos modelos organizacionais. Cumpre enfatizar a dificuldade de se pensar em tendências com respeito a um regime de acumulação abordando apenas um dos elementos que o compóem, sem considerar sua interaçáo com outros elementos igualmente importantes (como a regulação, o Estado, o trabalho). Ao mesmo tempo, sua análise restringe-se à difusão do modelo plataformizado no setor privado - o que impede que se desenhe um panorama geral dos riscos e das oportunidades que emergem desta nova forma de se organizar empreendimentos tanto públicos quanto privados.

O recorte recai sobre as empresas que se adaptaram ou emergiram como plataformas no regime de acumulação capitalista atual, marcado pela exploração econômica dos dados. Mais especificamente, sobre suas características microeconômicas e seus desdobramentos na dinâmica de competição intercapitalista. Para tanto, o autor relata elementos históricos que fundamentaram a emergência deste modelo de negócios (parte I), reflete sobre seus desdobramentos microeconômicos (parte II) e, brevemente, discute tendências e concisas projeçóes (parte III). Na segunda parte, a abordagem remonta à microeconomia heterodoxa: análise de modelos de empresa (plataformas), funçóes da empresa (as quatro características das plataformas), insumos básicos de produção (dados) e novos tipos de barreiras à entrada e competição (ecossistemas em silo, efeitos de rede). As quatro características gerais das plataformas são:

- $\quad$ sua atuação como organizadoras de mercados, afinal, elas são intermediárias - "provides the basic infrastructure to mediate between different groups" (SRNICEK, 2017, p. 44);

- $\quad$ efeitos de rede nos quais elas se fundamentam "the more numerous the users who use a platform, the more valuable that platform becomes for everyone else" (SRNICEK, 2017, p. 45). Os efeitos de rede geram naturalmente uma tendência à monopolização, afinal, uma plataforma é mais eficiente e atrai mais usuários quanto mais usuários ela possui - e o benefício para aqueles que interagem nela é maior quanto mais usuários interagirem nela; 
- subsídio cruzado: muitos serviços fornecidos náo são monetizados de forma a atrair mais usuários - e para isso outro braço da plataforma compensa aquele serviço gratuito aumentando seus preços;

- governança: as plataformas não apenas organizam os mercados a que se dedicam, mas também plasmam o formato que esse mercado tomará ao definirem as regras de interação, geração de valor e distribuição do valor dentro de seu ecossistema (SRNICEK, 2017, p. 47).

Haveria ao menos cinco grandes tipos de plataformas: de propaganda, nuvem, industriais, de produtos e enxutas (lean). Por fim, o autor projeta algumas tendências para a dinâmica concorrencial plataformizada: expansão da extração de dados, da capacidade de analisá-los e a formação de ecossistemas fechados (em contraposição à internet aberta).

Apesar de aportar dados e características interessantes, a tipologia proposta não segue critérios unidimensionais. Enquanto o grupo de plataformas de propaganda é definido em função de sua fonte de monetização, as plataformas industriais evocam uma definição mais tradicional, setorial, enquanto plataformas enxutas são identificadas pelo caráter não proprietário de ativos. Esta multidimensionalidade pode causar sobreposiçôes na classificação de plataformas (e.g.: uma eventual plataforma do setor industrial, sem ativos, cuja renda provém de propagandas, encaixa-se nos três grupos mencionados). Assim, tipologias calcadas em dimensões mais bem definidas, como o escopo organizacional (internas ou industriais) (GAWER, 2014) ou a capacidade de gerar inovação (inovativas, transacionais e híbridas) (CUSUMANO; GAWER; YOFFIE, 2019, capítulo III) oferecem critérios mais claros e operacionalizáveis. ${ }^{2}$

Embora fale de uma "economia de plataformas", o autor não menciona a possibilidade de pequenas e médias empresas prosperarem via plataformas que permitem baixos custos de internacionalização, ampliando seus mercados (UNCTAD, 2017 , p. 53). Srnicek não aborda a difusão das plataformas também no primeiro e no terceiro setor (estado e organizaçóes sociais). As possibilidades de se gerar bem-estar social no novo regime de acumulação são condicionadas também pela difusão do modelo plataformizado para outras esferas, além da empresa privada. $\mathrm{O}$ livro passa ao largo da transformação no provisionamento de serviços públicos via service dominant platforms (SDP), capaz de rebaixar custos operacionais, ampliar o acesso aos serviços públicos, democratizar a participação social na forma/conteúdo

2 Van Dijck et al. (2018) também oferecem uma boa tipologia. Os autores classificam as plataformas digitais em infraestruturais, que fornecem serviços essenciais tanto às outras plataformas como a empresas e atores sociais tradicionais e plataformas setoriais, com alcance e importância mais restritos (e.g., ao setor de saúde ou mobilidade urbana). 
dos serviços prestados e gerar inovação via processos de distribuição/descentralização massivos (massively distributed innovation) (TIWANA, 2014; YU et al., 2019; HAUTAMAKI; OKSANEN, 2018).

A principal lacuna da obra diz respeito à exploração parcial dos elementos envolvidos na formação do novo regime. Não é descabido criticar uma tentativa de se compreender o alcance de um regime de acumulação analisando-se apenas um de seus elementos constitutivos: a organização padrão empresarial. Embora seja um elemento central na constituição do regime, uma visão in toto exige complementar o estudo das empresas representativas com outros elementos, como o trabalho (BEARSON et al., 2019) e as normas elicitadas pelo novo papel do governo (VAN DIJCK; POELL; DE WAAL, 2018; ZYSMAN; KENNEY, 2018).

O livro contribui para compreendermos os limites de algumas tendências observadas, como as plataformas enxutas, hiperterceirizadas: acertadamente, o autor evidencia a insustentabilidade de seu modelo de negócios que até o momento não se provou lucrativo. Seu funcionamento é calcado em uma exacerbação do modelo apoiado pelo capital financeiro que busca valorizaçáo a qualquer custo (o que J. A. Schumpeter chamou de reckless banking e Carlota Perez chamou de fase de "frenesi"). Ao mesmo tempo, Srnicek reconhece que plataformas industriais e de produtos trazem "algo de novo" e perene para a dinâmica capitalista. O autor ressalta o papel das plataformas industriais na indústria 4.0 e o papel dos governos na coordenação de consórcios nacionais para o desenvolvimento do setor (GRUBER, 2019). Em outros termos, Srnicek traz evidências de quais elementos serão passageiros e quais serão perenes no novo regime.

Seu realismo quanto às exigências do modo de produção capitalista também são um ótimo contraponto ao fetichismo tecnológico ou ciberfetichismo (RENDUELES, 2016, p. 55) alardeado por alguns estudos da economia do compartilhamento que exageravam no otimismo, atribuindo à tecnologia digital a capacidade de resolver problemas eminentemente sociopolíticos. Procedendo dessa forma, Srnicek mantém os dois pés no chão ao situar-nos no estágio atual do capitalismo.

Finalmente, a principal virtude do livro é sua percepção de que mudanças nos regimes de acumulação - a evoluçáo capitalista de longo prazo - exigem mais do que inovações tecnológicas: também necessitam de inovaçóes organizacionais. $\mathrm{O}$ autor comenta como modelos organizacionais precedentes eram incapazes de lidar com dados e informações da maneira que a plataforma o faz. Avançando, Srnicek identifica na forma com que o regime anterior se exauriu e nas respostas político-econômicas às crises, a gênese da best-practice organizacional do regime atual. $\mathrm{O}$ 
declínio do ciclo anterior, conjugado às reaçóes empreendidas para conter a fase recessiva, dá forma ao surgimento do ciclo seguinte. Isso é algo que Simon Kuznets e outros neoschumpeterianos (PEREZ, 1983) já haviam percebido. Portanto, o livro contribui para o estudo das transformações de longo prazo do capitalismo.

Em suma, Platform capitalism é uma rica fonte de informaçôes sobre as plataformas, o regime de acumulação atual e aporta sobre este uma visão crítica. Srnicek não é normativo nesta obra. Talvez o escritor tenha percebido que era necessário investigar, descrever e explicar o fenômeno da plataformização antes de prescrever soluçôes para suas questôes. De fato, a obra cumpre com este objetivo: é uma boa primeira aproximação ao universo das plataformas digitais e aos novos desafios econômicos e sociais decorrentes de sua difusão.

\section{Referências}

BEARSON, D.; KENNEY, M.; ZYSMAN, J. New Work and value creation in the platform economy: a taxonomy and preliminary evidence. Berkeley, CA: Berkeley Roundtable on the International Economy, 2019 (BRIE Working Paper).

CUSUMANO, M.; GAWER, A.; YOFFIE, D. The business of platforms: strategy in the age of digital competition, innovation and power. Nova York: Harper Business, 2019.

GRUBER, H. Proposals for a digital industrial policy for Europe. Telecommunications Policy, v. 43, n. 2, p. 116-127, 2019.

HAUTAMAKI, A.; OKSANEN, K. Digital platforms for restructuring the public sector. In: SMEDLUND, A.; LINDBLOM, A.; MILTRONEN, L. (ed.). Collaborative value cocreation in the platform economy. Springer, 2018.

PEREZ, C. Structural change and the assimilation of new technologies in the economic and social systems, Futures, v. 15, n. 5, p. 357-375, 1983.

RENDUELES, C. Sociofobia: mudança política na era da utopia digital. São Paulo: Ediçóes Sesc São Paulo, 2016.

SRNICEK, N. Platform capitalism. Cambridge: Polity Press, 2017.

TIWANA, A. Platform ecosystems: aligning architecture, governance, and strategy. Waltham, MA: Morgan Kauffman, 2014.

UNCTAD. Information Economy Report 2017: digitalization, trade and development. Switzerland: United Nations, 2017. 
VAN DIJCK, J.; POELL, T.; DE WAAL, M. Platform society: public values in a connective world. Nova York: Oxford University Press, 2018.

ZYSMAN J.; KENNEY, M. The next phase in the digital revolution: intelligent tools, platforms, growth, and employment. Communications of the Association of Computing Machinery, v. 61, n. 2, p. 54-63, 2018.

YU, J. et al. Towards a service-dominant platform for public value co-creation in a smart-city: evidence from two metropolitan cities in China. Technological Forecasting \& Social Change, v. 142, p. 168-182, 2019.

\section{(cc) EY-NC}

Esta obra foi licenciada sob uma Licença Creative Commons Atribuição-NãoComercial 3.0 Brasil. 